\title{
Commentary: The AVIATOR Registry: The right way to change perspective
}

Michele Di Mauro, MD, PhD, ${ }^{a}$ Giuseppe M. Raffa, MD, ${ }^{\mathrm{b}}$ Massimiliano Foschi, MD, ${ }^{\mathrm{a}}$ and Antonio M. Calafiore, MD

From the ${ }^{\mathrm{a}}$ Heart Department, SS Annunziata Hospital, Chieti; ${ }^{\mathrm{b}}$ Department for Treatment and Study of Cardiothoracic Diseases and Cardiothoracic Transplantation IRCCS-ISMETT, Palermo; and ${ }^{\mathrm{c}}$ Cardiac Surgery Department, Pope John Paul II Foundation, Campobasso, Italy.

Disclosures: Authors have nothing to disclose with regard to commercial support.

Received for publication Nov 28, 2018; accepted for publication Nov 28, 2018; available ahead of print Jan 16, 2019.

Address for reprints: Michele Di Mauro, MD, PhD, Heart Department, SS Annunziata Hospital, Via dei Vestini, 66100, Chieti, Italy (E-mail: mdimauro1973@gmail.com).

J Thorac Cardiovasc Surg 2019;157:2212-3

$0022-5223 / \$ 36.00$

Copyright $(c) 2018$ by The American Association for Thoracic Surgery

https://doi.org/10.1016/j.jtcvs.2018.11.116

Aortic regurgitation (AR) ranges from $2 \%$ to $30 \%$ in United States, but severe AR, which is the real target of surgery, is estimated between 5\% and 10\%. ${ }^{1}$ Data from Euro Heart Survey confirm this prevalence even in Europe, showing as roughly $10 \%$ of patients with valvular heart disease have moderate or more AR. However, the vast majority of patients with severe AR undergoing surgery receive aortic valve (AV) replacement, with only about $2 \%$ of cases submitted to AV repair. ${ }^{2}$

This attitude is completely opposite that adopted by cardiac surgeons in relation to mitral and tricuspid regurgitation. Even if it is indeed well-known that AV repair techniques are more technically demanding, the results of $\mathrm{AV}$ repair, in selected patients, are so good that they have to persuade the surgeons to perform more $\mathrm{AV}$ repair.

In type $\mathrm{I}^{3} \mathrm{AR}$, the main mechanisms underlying the central incomplete cusps coaptation are the enlargement annulus and sinotubular junction; in this case, the 2 possible approaches, remodeling and reimplantation techniques, showed both an outstanding outcome, with freedom from reoperation of $96 \%$ at 20 years (reimplantation) ${ }^{4}$ and even $99 \%$ at 7 years (remodeling with external ring annuloplasty). ${ }^{5}$ Even if in type II AR, AV replacement is still the gold standard, some dedicated experiences showed good outcome (freedom from reoperation $97.4 \%$ at 7 years) adding annuloplasty to valvuloplasty. ${ }^{6}$

Patients with tricuspid or bicuspid dystrophic AR, accounting for approximately two-thirds of cases, especially in the Western countries, are usually good candidates for AV repair; however, the European Association for CardioThoracic Surgery and the European Society of Cardiology recommend to adopt a dedicated "Heart Team" to selected patients in whom AV repair may be a feasible alternative to valve replacement (Class IC indication). ${ }^{7}$

The AVIATOR Registry ${ }^{8}$ (supported by the Heart Valve Society) is an open registry with 2 aims: (1) to provide an epidemiologic picture of patients with AR and (2) to

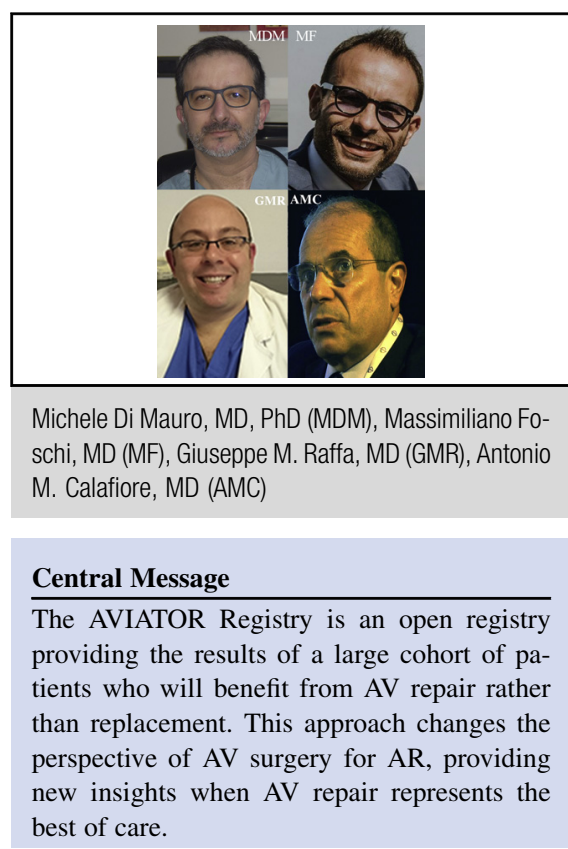

See Article page 2202.

analyze large homogeneous cohorts of patients who will benefit from AV repair rather than replacement either in case of isolated or combined AR with aortic aneurysm.

This approach changes the perspective of AV surgery for $\mathrm{AR}$, and finally surgeons can have some new insights from a large cohort of patients with AR in whom AV repair represents the best of care to use this information as a clinical tool in their daily practice. Moreover, this registry could reveal to us how much the success and the durability of AV repair are either valve degeneration severity or dependent on the surgeon's skill.

The main weakness of the AVIATOR is that the prevalence of AV replacement is too small to realize any comparison, which is enlightening, as most the participating centers are more devoted to AV repair than AV replacement, and this could be a great bias. Nevertheless, the AVIATOR registry represents the first international represents the first attempt to change perspective in the approach to AV repair.

\section{References}

1. Maurer G. Aortic regurgitation. Heart. 2006;92:994-1000.

2. Iung B, Baron G, Butchart EG, Delahaye F, Gohlke-Bärwolf C, Levang OW, et al. A prospective survey of patients with valvular heart disease in Europe: the Euro heart survey on valvular heart disease. Eur Heart J. 2003;24:1231-43. 
3. le Polain de Waroux JB, Pouleur AC, Goffinet C, Vancraeynest D, Van Dyck M, Robert A, et al. Functional anatomy of aortic regurgitation: accuracy, prediction of surgical repairability, and outcome implications of transesophageal echocardiography. Circulation. 2007;116(11 suppl): I264-9.

4. David TE, David CM, Feindel CM, Manlhiot C. Reimplantation of the aortic valve at 20 years. J Thorac Cardiovasc Surg. 2017;153:232-8.

5. Lansac E, Di Centa I, Sleilaty G, Lejeune S, Berrebi A, Zacek P, et al. Remodeling root repair with an external aortic ring annuloplasty. J Thorac Cardiovasc Surg. 2017; $153: 1033-42$
6. Lansac E, Di Centa I, Sleilaty G, Lejeune S, Khelil N, Berrebi A, et al. Long-term results of external aortic ring annuloplasty for aortic valve repair. Eur J Cardiothorac Surg. 2016;50:350-60.

7. Falk V, Baumgartner H, Bax JJ, De Bonis M, Hamm C, Holm PJ, et al. 2017 ESC/ EACTS Guidelines for the management of valvular heart disease. Eur J Cardiothorac Surg. 2017;52:616-64.

8. de Heer F, Kluin J, Elkhoury G, Jondeau G, Enriquez-Sarano M, Schäfers HJ, et al. AVIATOR: an open international registry to evaluate medical and surgical outcomes of aortic valve insufficiency and ascending aorta aneurysm. J Thorac Cardiovasc Surg. 2019;157:2202-11.e7. 